\title{
Plantas com Acção Insecticida
}

\section{Introdução}

O homem recorre ao uso de compostos com acção biocida (vulgarmente designados por pesticidas) desde que se tornou sedentário e começou a cultivar a terra. Mas foi no fim do século XIX que a luta contra as pragas (ou pestes) se tornou mais importante com a aplicação de produtos químicos como arseniatos, óleos minerais, substâncias derivadas de espécies vegetais, etc. Após a $2 .^{\circ}$ Guerra Mundial, devido ao avanço na química de síntese, introduziram-se os pesticidas de origem sintética. Os pesticidas usados nos anos quarenta como por exemplo hidrocarbonetos clorados, carbamatos, organofosfatos e outros, tiveram um papel importante no aumento do rendimento das culturas. $\mathrm{O}$ uso indiscriminado destes compostos químicos criou sérios problemas ao homem devido à toxicidade, persistência no meio, contaminação das águas, acumulação nos tecidos adiposos dos animais e do homem, aparecimento de resíduos nos alimentos e resistência aos próprios insecticidas. Pelas razões expostas, os pesticidas naturais têm hoje um papel importante na luta contra as pragas mantendo o equilíbrio ecológico. São produzidos por plantas, insectos ou por microorganismos, muitas vezes para defesa e sobrevivência e também para crescimento e desenvolvimento.

Ao abordar este tema pretende-se apenas dar uma ideia geral dos tipos de insecticidas, de origem vegetal, com maior aplicação na agricultura. Existem variadíssimas plantas que podem fornecer substâncias capazes de provocar a morte dos insectos, conhecendo-se mais de duas mil espécies com aç̧ão insecticida. Estes produtos podem actuar directamente (piretrina, rotenona e nicotina) ou de forma indirecta (compostos antifágicos, hormonas juvenis, hormonas anti-juvenis).

\section{Piretrinas}

O piretro é um produto obtido das folhas de Chrysanthemum cineraiifolium, C. roseum e C. marsehali (família das Asteraceae). É constituído por vários componentes com a denominação de pitetrinas que, quimicamente, são ésteres orgânicos resultantes da combinação dos ácidos crisantémico ou pirético com três ceto-alcoois (piretrolona, jasmolona ou cineralona).

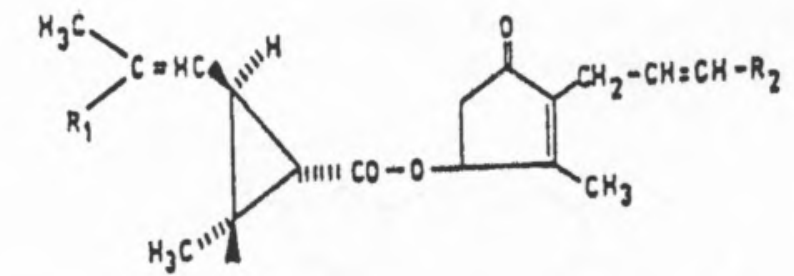

$$
\begin{array}{llllll} 
& \mathrm{R}_{1} & \mathrm{R}_{2} & & \mathrm{R}_{1} & \mathrm{R}_{2} \\
\text { Piretrina } & \mathrm{CH}_{3} & \mathrm{CH}=\mathrm{CH}_{2} & \text { Cirenina II } & \mathrm{COOCH}_{3} & \mathrm{CH}_{3} \\
\text { Piretrina II } & \mathrm{COOCH}_{3} & \mathrm{CH}=\mathrm{CH}_{2} & \text { Jasmolina I } & \mathrm{CH}_{3} & \mathrm{CH}_{2}-\mathrm{CH}_{3} \\
\text { Cirenina I } & \mathrm{CH}_{3} & \mathrm{CH}_{3} & \text { Jasmolina II } & \mathrm{COOCH}_{3} & \mathrm{CH}_{2}-\mathrm{CH}_{3} \\
& & &
\end{array}
$$

Estes compostos têm a desvantagem de perderem rapidamente a sua acção insecticida, pois sob a acção da luz e do ar sofrem inúmeros rearranjos. Ultrapassou-se este problema por modificação química das piretrinas obtendo-se então os piretróides. Os piretróides são o grupo de pesticidas que recentemente maior desenvolvimento tiveram, representando hoje um terço da utilização de insecticidas a nível mundial. Muitas vezes têm uma potência superior às piretrinas naturais e continuam a ser biodegradáveis como os produtos de partida.
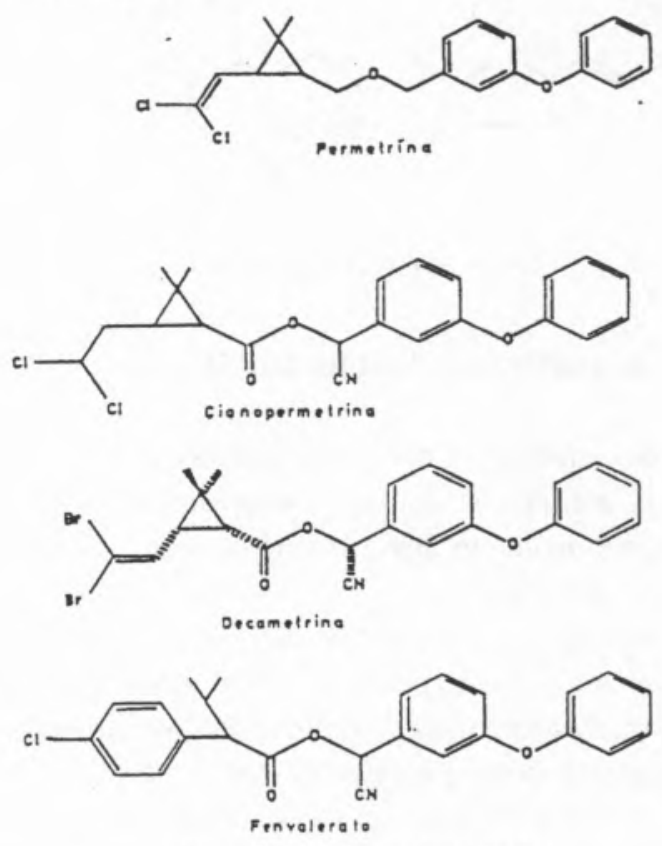

Piretróides mais comercializados

\footnotetext{
assistente da Faculdade de Farmácia de Lisboa.
} 


\section{Rotenona}

A rotenona obtém-se de espécies de géneros Derris, Lonhocarpus e Tephrosia (família das Leguminoseae). Estas plantas contêm na raiz retenona ou então compostos estruturalmente muito semelhantes (rotenóides). A rotenona é quimicamente uma cetona pentacíclica e é praticamente inofensiva para o homem, plantas e animais domésticos. $\mathrm{O}$ uso dos insecticidas sintéticos causou uma grande diminuição no consumo de rotenona. No entanto esta ainda continua a ser comercializada sob diversas formas inclusivamente em "sprays" para uso doméstico e até juntamente com outros insecticidas naturais como por exemplo as piretrinas.<smiles>C=C(C)[C@@H](C)Oc1ccc2c(c1C)O[C@H]1COc3cc(OC)c(OC)cc3[C@H]1C2=O</smiles>

\section{Nicotina}

Das espécies Nicotiana tabacum e $N$. rustica (família das Solanaceae) são extraídos os alcaloides nicotina, nornicotina e anabasina. Estes têm uma acção insecticida muito eficaz, são degradáveis e não criam resistência nos insectos. Têm, no entanto, o inconveniente de apresentarem acções farmacológicas e toxicológicas diversas para o homem pelo que o seu uso tem vindo a ser cada vez mais restringido.

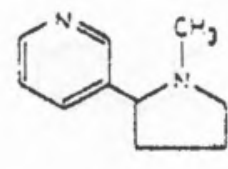

(a)

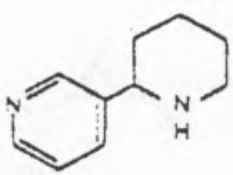

(b)
Nicotina (a) e Anabasina (b)

\section{Compostos antifágicos ("antifeedant")}

Um dos mecanismos de defesa das plantas é a produção de compostos antifágicos ou seja compostos químicos que, apesar de não matarem directamente os insectos, impedem que eles se alimentem.

Um antifágico já existente no mercado mas ainda usado em pequena escala é o triterpenoide "azadirachtin" retirado da espécie Azadirachta indica (família das Meliaceae), uma árvore de grande porte que existe na Ásia Tropical, América, Austrália e África. Durante anos as suas folhas foram usadas pelas populações para afastarem os insectos das produções agrícolas. Este triterpenoide foi mais tarde detectado também na espécie Melia azedarach (família das Meliaceae).

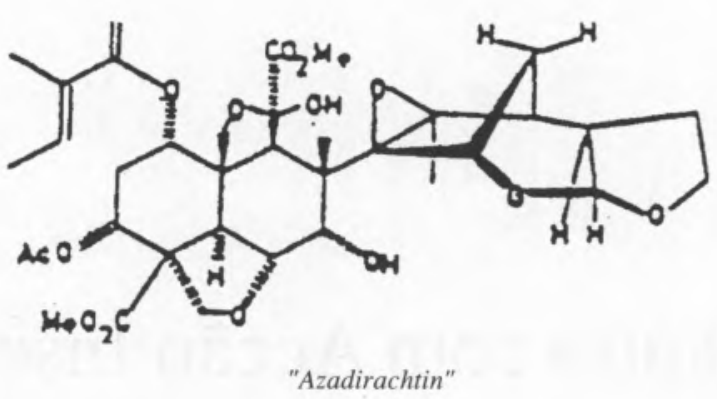

Para além dos terpenos - o maior grupo de antifágicos - têm vindo a ser isolados numerosos compostos com esta acção pertencentes a diversas classes de produtos naturais: alcaloides, flavonoides, fenois, etc.

\section{Hormonas juvenis e hormonas anti-juvenis}

O estudo da fisiologia dos insectos levou à identificação das suas hormonas juvenis e hormonas da muda bem como ao isolamento de compostos análogos a partir de espécies vegetais. No entanto a acção insecticida destes compostos não é satisfatória, pois além de actuarem tarde demais para evitar que o insecto prejudique a cultura, são muito instáveis.
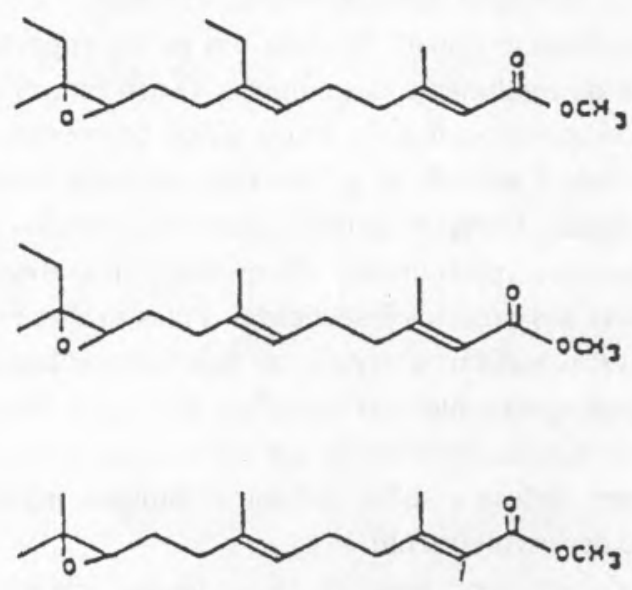

(a)

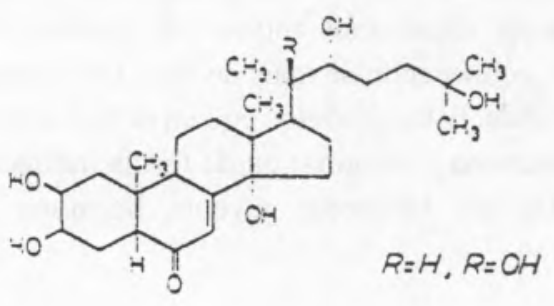

(b)

Hormonas juvenis (a) e hormonas de muda (b)

Posteriormente surgiu a ideia de que compostos químicos bloqueadores da produção das hormonas juvenis pudessem ter acção insecticida. Em 1976 Bowers isolou da planta Ageratum houstonianium (família das Asteraceae) os precocenos I e II que foram denominados de hormonas anti-juvenis. 


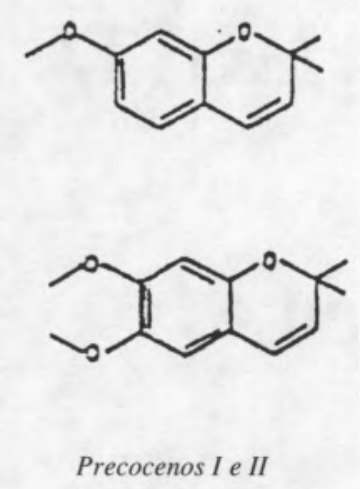

Estes compostos que devem a sua acção ao facto de serem citotóxicos e de provocarem a degeneração da glândula "corpus allatum". A utilização dos precocenos vai causar uma maturação prematura dos insectos tornando-os estéreis e diminuir o tempo de vida da larva, o qual corresponde ao estádio dos insectos mais prejudicial à cultura.

Apesar destes compostos não actuarem como hormonas antijuvenis sobre todos os insectos, eles abrem perspectivas de um novo modo de controle de pragas, sendo considerados por alguns especialistas como a quarta geração de pesticidas.

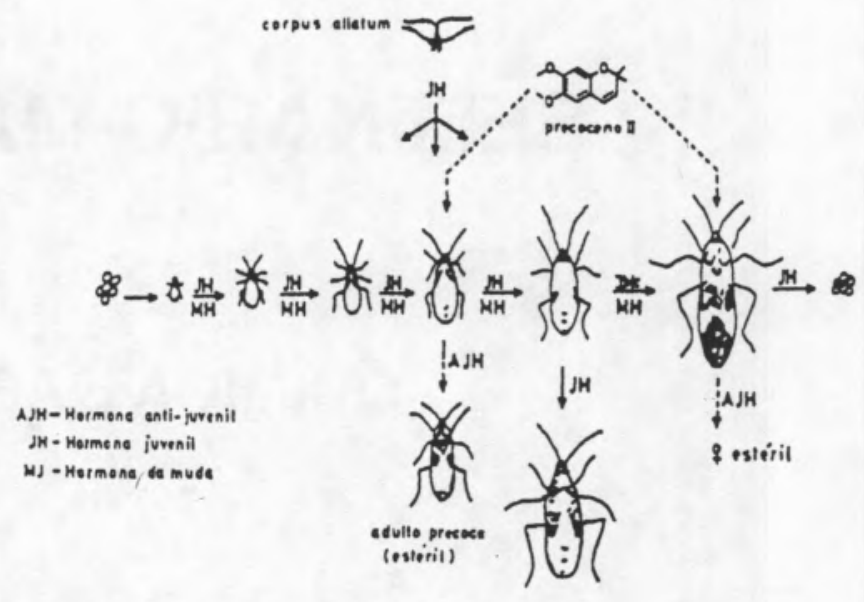

Acçâo dos precocenos

Bibliografia

- Galeffi, C.; Marini Bettolo, G.G. "New approaches to the utilization of plants in the preparation of pharmaceuticals and insecticides", Fitoterapia, volume LIX, n.ำ 3 (1988).

-Murta Martins, R.M. e Campos Neves, M.T. "A toxicidade dos Pesticidas II. Principais acções tóxicas de alguns pesticidas mais comuns". Revista Portuguesa de Farmácia, vol. XXXIX, n.ํำ (1989).

- Mendes, M. "Eduarda, "Uso de substâncias naturais no combate a pragas", LNETI, $\mathrm{n}^{\circ} 4$ (1989).
PROMÉCIO, de Prometeus; descoberto em 1947; é a única "terra-rara" que nunca foi encontrada na natureza. Produzida em reactores nucleares, o promécio radioactivo é usado em "baterias atómicas", para instrumentos dirigíveis de mísseis, relógios e rádios.

SAMÁRIO, do mineral samarokite, derivado, por sua vez, do nome de uma mina russa baptizada pelo coronel V.E. Samarsky; descoberto em 1879. Cristais de cloreto de cálcio tratados com samário têm sido usados em lasers - aparelhos para produzir raios suficientemente intensos para fundir metais ou estalar a lua.

EURÓPIO, de Europa, descoberto em 1896. É a "terra-rara" mais reactiva. Este metal não tinha virtualmente uso prático até à idade atómica. No entanto, os átomos de európio podem absorver mais neutrões do que qualquer outro elemento, o que torna este elemento valioso no controlo de reactores nucleares.

GADOLÍNIO, do mineral gadolinite, baptizado por um químico finlandês; descoberto em 1880. o Gadolínio encontra-se no meio das "terras-raras", dividindo-as em metais leves, que conferem flexibilidade às ligas metálicas, e metais pesados, usados principalmente como agentes de tenacidade. 


\section{SEMINÁRIO MANUELA MOTTA}

\section{QUÍMICA DAS SUPERFÍCIES}

13 de Dezembro de 1991

- Conferências convidadas

- Intervenções livres

ORGANIZAÇÃO DA ÁREA DEPARTAMENTAL DE CIÊNCIAS EXACTAS DA UNIVERSIDADE DE ÉVORA

Para mais informações contactar Prof. Rui Namorado Rosa

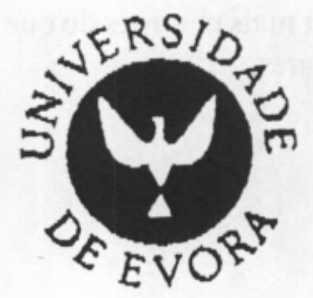

UNIVERSIDADE DE ÉVORA

Largo dos Colegiais, n.․ $2-7000$ ÉVORA, Portugal

Telefones: 351-66-25572 / 3 / 4; 28570 / 1 / 2

Telefax: 351-66-20775 